\title{
Phenotypic changes in spring arrival: evolution, phenotypic plasticity, effects of weather and condition
}

\author{
Francisco Pulido* \\ Netherlands Institute of Ecology (NIOO-KNAW), PO Box 40, 6666ZG Heteren, The Netherlands
}

\begin{abstract}
Global climate change is having a major impact on the viability of species. Whether a particular population will survive or go extinct will depend on its potential to adapt to new environmental conditions. In migratory birds, the timing of spring migration is one of the major determinants of the timing of reproduction, and, as spring temperatures increase, we expect birds to return earlier to their breeding grounds. In accord with this expectation, the timing of spring arrival has advanced in many bird populations within the last $30 \mathrm{yr}$. Yet, despite the presence of genetic variation in the timing of migration and fitness advantages in birds arriving early, we still lack conclusive evidence for evolutionary change. One reason for this may be that weather conditions en route, particularly the direction and speed of winds, have an important influence on individual migration speed. Moreover, there is strong evidence that physical condition may modify the timing of departure from the wintering grounds, migration speed and ultimately the timing of arrival and breeding. We also expect nestling condition and maternal effects to influence spring migration timing. Long-term population studies monitoring individual arrival in combination with experimental approaches will be needed to tease apart genetic and different environmental effects on the traits determining migration timing. This knowledge will be crucial for predicting adaptive responses of the timing of spring arrival in the future.
\end{abstract}

KEY WORDS: Climate change • Bird migration · Evolution · Adaptation · Genetic variation • Selection $\cdot$ Phenotypic plasticity $\cdot$ Physical condition

\section{INTRODUCTION}

Global climate is changing at an unprecedented rate. The increase in temperature in the Northern Hemisphere over the second half of the 20th century has been the largest in the past $500 \mathrm{yr}$, and the past decade, in particular, has been the warmest on record (Solomon et al. 2007). These recent climatic alterations are having a measurable impact on the distribution, ecology and behaviour of animals (Walther et al. 2002, Parmesan \& Yohe 2003, Parmesan 2006). In view of a persistent increase in temperature, we expect profound changes in ecosystems and, as a consequence, of biodiversity (Parry et al. 2007). Organisms that cannot adapt to these rapid alterations of their environment (see Pulido \& Berthold 2004, Visser \& Both 2005) are likely to go extinct (Both et al. 2006a). For predicting whether particular species will respond to environmental changes, and to what extent the response may be limited, we need to understand the mechanisms by which organisms adapt to changing environments (Gienapp et al. 2007, Gordo 2007, both this issue).

In many areas, particularly in Europe and North America, spring events such as budburst and the hatching of caterpillars have been occurring earlier over the course of the last 30 yr (Menzel et al. 2006, Schwartz et al. 2006, van Asch \& Visser 2007). Many birds have advanced their timing of reproduction in response to these changes in the seasonal availability of food. Yet, the observed changes have rarely been of the same magnitude as those in their prey species, which has led to an asynchrony between the demand for food and its availability (reviewed by Visser et al. 2004, Visser \& Both 2005). A number of studies suggest 
that recent advances in breeding times have been smaller in long-distance migrants than in short-distance migrants or resident bird species (Lehikoinen et al. 2004, Pulido \& Widmer 2005, Rubolini et al. 2007, this issue). Thus, the offspring of many migratory birds are increasingly raised under suboptimal conditions. Populations of migratory birds, particularly those that migrate long distances, are steadily declining (Berthold et al. 1998, Sanderson et al. 2006), and it is likely that the challenge to adapt to rapidly changing environmental conditions will aggravate the impacts of other anthropogenic threats, such as habitat loss, fragmentation and deterioration (Berthold 1998, Pulido \& Widmer 2005, Jetz et al. 2007). One potential constraint on the speed of adaptive change in the timing of breeding is the rate of change in spring arrival (Both \& Visser 2001, Coppack \& Both 2002, Sanz et al. 2003, Weidinger \& Král 2007). It is suggested that the use of temperature-independent environmental cues, e.g. daylength, for initiating seasonal events (Coppack \& Both 2002); lack of phenotypic plasticity (Pulido \& Widmer 2005) and lack of genetic variation (Berthold 1995) in the endogenous programme controlling migration; or differences in the rate and direction of temperature changes along the migration route (Strode 2003, Pulido \& Berthold 2004, Both \& te Marvelde 2007, this issue) could hamper the immediate response of migration phenology to selection for earlier arrival. However, to date, no study has attempted to gauge the importance of these different factors for determining spring arrival. The question is whether migratory birds will be able to shift their arrival dates forward, and thereby advance laying-dates, to maintain or restore synchrony of their offspring's demands with the availability of food. To answer this question we need to know how migratory birds modify the timing of migration and which mechanisms could limit the response to climatic alterations.

To date, there are about 90 original publications concerned with the impact of recent climate change on the timing of bird migration. More than half of these studies have been published within the last 4 yr. Given this spectacular increase in studies reporting phenological changes in the timing of spring migration in the past decade (see reviews by Lehikoinen et al. 2004, Zalakevicius et al. 2006, Gordo 2007, Rubolini et al. 2007), many of them being merely descriptive, there is a need to evaluate the importance of different adaptive mechanisms and to identify the areas towards which we need to direct our future research.

In this perspective, I will first discuss to what extent the prerequisites for adaptive evolutionary changes in the timing of spring migration are met and give examples for such changes. Secondly, I will give an overview of the mechanisms that may underlie observed correlations between arrival date and weather vari- ables and discuss the role of phenotypic plasticity and its potential evolution. Thirdly, I will evaluate the importance of physical condition for changes in the timing of spring arrival and expound on how condition effects may impact adaptive evolution and complicate the prediction of adaptive change.

\section{ADAPTIVE EVOLUTION OF THE TIMING OF SPRING MIGRATION}

Adaptive evolution is the result of natural selection. Natural selection is a process that will work if there is phenotypic variation in a population, if this variation is correlated with fitness differences and if it is heritable (cf. Endler 1986). Rapid evolutionary changes in the wild have been demonstrated repeatedly (Kinnison \& Hendry 2001, Hairston et al. 2005, Hendry et al. 2008), but there are a number of factors that may prevent evolutionary change or its detection, such as environment-induced plasticity, fluctuating selection or antagonistic genetic correlations (Merilä et al. 2001a). Numerous approaches can potentially be used to detect natural selection and evolutionary change (see Endler 1986, Reznick \& Travis 1996, Gienapp et al. 2007, 2008), of which long-term monitoring of behaviour and reproductive success of marked individuals, and common-garden and reciprocal transplant experiments are probably the most useful means of studying changes in bird migration (Pulido \& Berthold 2003, van Noordwijk et al. 2006). Unfortunately, these approaches have hitherto hardly been followed for studying changes in avian migration timing, so that currently we have only circumstantial evidence for adaptive evolution. Nevertheless, we may be able to predict whether evolutionary changes are to be expected in a particular population if we know the amount of phenotypic and genetic (co)variation and the strength and direction of selection.

\subsection{Phenotypic variation}

Most studies reporting phenological shifts in spring migration cannot draw inferences about the causes of these changes because they are based on first arrival records that do not bear any information on the level and patterns of variation within a population (see Lehikoinen et al. 2004). However, there are some studies that have monitored the complete arrival distribution, or at least characteristic parts of it, such as the median, the quartiles and the 10 and $90 \%$ or 5 and $95 \%$ percentiles (see Ahola et al. 2004, Vähätalo et al. 2004, Sparks et al. 2005, Jonzén et al. 2006, Rainio et al. 2006, Tøttrup et al. 2006). These studies indicate 
that there is considerable phenotypic variation in spring passage and arrival phenology and that the rate of change may vary considerably between individuals of a population and between species migrating at different times, or differing in migration distance or route (Lehikoinen et al. 2004, Rubolini et al. 2007, Sparks \& Tryjanowski 2007, this issue).

In time-constrained, long-distance migrants, arrival and establishment of territories by males typically takes place within a short period of about 2 to $3 \mathrm{wk}$ in spring (Potti 1998, Widmer \& Biebach 2001, Smith \& Moore 2005). This small variation, which may cause problems in the analysis of data if arrival time cannot be recorded accurately, is large enough to cause strong variation in fitness within a population (see Section 2.5). There is some evidence indicating that phenotypic variation in spring migration phenology is larger in short-distance than in long-distance migrants (Hagan et al. 1991). This has become apparent in field studies, but is also supported by the results of a commongarden experiment with Sylvia warblers. A comparison of phenotypic and genetic variation in the timing of autumn migratory activity in 2 garden warbler Sylvia borin and 1 blackcap Sylvia atricapilla populations revealed that phenotypic variation was significantly lower in the garden warbler populations. This canalization of migration timing in the long-distance migrant was not due to a reduction in genetic variation, but was a consequence of stronger buffering of phenotypic expression against environmental perturbation (Pulido \& Widmer 2005).

One general problem in the interpretation of phenological data from bird observatories or trapping stations is the mix of individuals from different breeding populations, particularly when they are trapped far away from the breeding sites. The observed distribution of arrival or passage dates of a particular species at a particular site may then actually be a compound of a number of different distributions. As a consequence, observed changes in the mean and variance may not bear any information on changes in migration phenology of a particular population but, may reflect changes in the composition of the population on passage (Both 2007). But, not only the heterogeneity of a population on passage, being composed by individuals from different breeding populations differing in their optimal arrival, may cause problems in the interpretation of results. A composite distribution of arrival or passage dates at a site may also result from differences in spring migration phenology between males and females and between age classes within a population. Differential timing of spring migration is widespread, males typically migrating before females and older individuals before first-year birds (Morbey \& Ydenberg 2001, Stewart et al. 2002). Phenotypic and genetic variance in arrival date, selection, and ultimately, in the rate of adaptive change may vary among the sexes and between different age groups (Møller 2007, but see Rainio et al. 2007, this issue), particularly if they differ in their life histories; for instance, if males do not breed in their first year (F. Pulido, C. Both, M. E. Visser unpubl. data).

\subsection{Repeatability of the timing of spring migration}

An indicator of whether phenotypic variation in a population, for instance, among years or habitats, is caused by among-individual variation in the physiological response to the environment, by variation in environmental conditions, or due to genetic differences is the repeatability (Boag \& van Noordwijk 1987). Repeatability is a measure for the consistency of individual behaviour under different environmental conditions (e.g. different years, different habitats, etc.), and may set an upper limit for the heritability of a trait. Moreover, repeatability is a measure of the robustness of trait expression against environmental variation and may reflect the precision of measurement. Repeatability is estimated from the ratio of among-individual phenotypic variation to total variation, i.e. the sum of within-individual and among-individual variation, whereby phenotypic variation can be corrected for the effect of particular environmental variables, thus allowing one to draw inferences about individual consistency and among-individual variation in the response to this variable (Falconer \& Mackay 1996, van Noordwijk et al. 2006).

Repeatability of arrival date and traits associated with the timing of spring migration is moderate to low (mean repeatability $=0.293, \mathrm{SD}=0.195, \mathrm{CI}_{95 \%}=0.143$, 0.443 , see Table 1). Low repeatability suggests that environmental variation is the cause of a large proportion of phenotypic variation in migration phenology. The large variance among estimates could indicate that among-population or among-year differences in the strength of environmental effects are important. However, a closer look reveals that low repeatabilities are predominantly found in studies where only a few individuals were monitored over a large number of years (e.g. whooper swans, see Table 1). As repeatability decreases with time, this could be an explanation for very low estimates reported by some studies. Heterogeneity in repeatabilities among studies may also result from variation in the precision of measurements. In populations for which it is particularly difficult to record arrival, low repeatabilities may result from large measurement errors (Pulido \& Berthold 2003). Whether or not a bird can be detected just after completing migration will very much depend on 
Table 1. Repeatabilities of spring arrival date (Arr) and traits related to spring phenology. Dep: departure from wintering grounds; Dur: duration of spring migration; Dep $\mathrm{sa}_{\mathrm{s}}$ and $\mathrm{Dur}_{\mathrm{sa}}$ : departure and duration of migration from staging area, respectively. N: number of ind. Significance levels: ${ }^{\mathrm{ns}} \mathrm{p}>0.05,{ }^{*} \mathrm{p}<0.05,{ }^{* *} \mathrm{p}<0.01,{ }^{* * *} \mathrm{p}<0.001$. Values in brackets give correlation between individual arrivals in 2 consecutive years

\begin{tabular}{|lllccll|}
\hline Trait & \multicolumn{1}{c}{ Species } & \multicolumn{1}{c}{ Population } & N & Repeatability & Method & Source \\
\hline Arr & Anser caerulescens atlanticus & Nunavut, Canada & 20 & $0.42^{*}$ & Radio tracking & Bêty et al. (2004) \\
Arr & Recurvirostra avoseta & Germany & 16 to 32 & 0 to 0.29* & Ringing, observation & Hötker (2002) \\
Arr & Limosa limosa islandica & Iceland & 46 & $0.18^{* * *}$ & Ringing, observation & Gunnarsson et al. (2006) \\
Arr & Hirundo rustica & Denmark & 24 & $0.51^{* * *}$ & Ringing, observation & Møller (2001) \\
Arr & Pterochelidon pyrrhonota & Nebraska, USA & 14031 & $0.11^{* * *}$ & Capture & Brown \& Brown (2000) \\
Arr & Ficedula hypoleuca & Spain & 39 & $0.08^{\text {ns }}$ & Ringing, observation & Potti (1998) \\
Arr & Phylloscopus fuscatus & Magadan, Russia & 12 & $0.34^{\mathrm{ns}}$ & Ringing, observation Forstmeier (2002) \\
Arr & Vireo griseus & Virginia, USA & 32 & $(0.62)^{* * *}$ & Ringing, observation & Hopp et al. (1999) \\
Dep & Anser caerulescens atlanticus & Nunavut, Canada & 36 & $-0.02^{\mathrm{ns}}$ & Radio tracking & Bêty et al. (2004) \\
Dep & Cygnus columbianus bewickii & United Kingdom & 67 & $0.06^{* *}$ & Ringing, observation & Rees (1989) \\
Dep & Limosa limosa baueri & New Zealand & 44 & $0.83^{* * *}$ & Ringing, observation & Battley (2006) \\
Dur & Anser caerulescens atlanticus & Nunavut, Canada & 20 & $0.37^{*}$ & Radio tracking & Bêty et al. (2004) \\
\hline
\end{tabular}

whether it flies directly to the nesting site, or if it feeds more or less close to the breeding sites for a certain period. The strategy used may depend on the size and ecology of the species and the availability of food in the breeding habitat, but it may also vary from year to year depending on the environmental conditions (Klaassen et al. 2006). This among-year variation in the detectability of arrival could be an additional cause of low repeatability of arrival date in the wild. Under controlled conditions individual consistency of migratory behaviour may be higher (Pulido et al. 2001a, Bertin et al. 2007)

Of particular interest is the comparison of repeatabilities among groups of individuals within a population, as variation in the repeatability of a trait may give us insights into the ecological conditions determining plasticity or canalization of trait expression (van Noordwijk et al. 2006). Thus, repeatability may vary among individuals that differ in migratory behaviour. In pied avocets Recurvirostra avosetta breeding in northern Germany, for instance, arrival date was repeatable in males wintering in southern areas, i.e. Iberia and Morocco, but not in females or in males wintering in the north (Hötker 2002). One possible explanation for this difference in among-year repeatability between male avocets wintering at different latitudes is their difference in the response to temperatures at the breeding grounds, which had no effect on arrival date in males wintering in the south. Males wintering in the north tended to arrive earlier in years with warm springs. Hötker (2002) hypothesized that this difference in the response of pied avocet arrival to weather conditions at the breeding sites could be due to the difference in the strength of the correlation between weather fluctuations in the breeding and the wintering areas. Birds wintering close to the breeding area will gain some information on the progression of spring, while birds wintering further away will experience weather conditions that are unrelated to conditions at their breeding sites. Yet it is unclear, whether these 2 groups of avocets wintering at different latitudes respond differently to weather conditions in winter and on migration, i.e. whether they differ in phenotypic plasticity. A similar explanation was put forward for explaining the difference in the rate of change in spring migration between short-distance and long-distance migrants (see, for instance, Hüppop \& Hüppop 2003). In line with this hypothesis is the finding that Danish great cormorants Phalcrocorax carbo wintering locally show less yearto-year consistency in arrival date than birds wintering at some distance from the breeding grounds (Bregnballe et al. 2006). However, in an among-species comparison based on published repeatability estimates (see Table 1) I did not find an association between the repeatability of arrival date and migration distance $\left(\mathrm{r}_{\mathrm{s}}=0.151, \mathrm{n}=9, \mathrm{p}=0.70\right)$. This does not necessarily refute Hötker's hypothesis, as differences among studies in sample sizes, methods used and species investigated may have masked any effect.

To gain a better understanding of the extent to which exogenous (e.g. weather, food availability, etc.) and endogenous factors control the timing of spring migration, we need to estimate repeatabilities at the different stages of migration. This is currently only possible in large birds that can be followed by satellite telemetry. With this technique single birds, like storks, have been followed for up to 12 migratory journeys (Berthold et al. 2004). These studies have revealed that plasticity in individual migratory behaviour is very high, not only in the timing of migration, but also in the use of migration routes and wintering areas (Berthold et al. 2002, 2004, Meyburg et al. 2004, Alerstam et al. 2006). Yet, no attempt has been made to use this technique to quantify within-individual and among-indi- 
vidual variability of migratory traits that cannot not be measured by other means, probably because so far only few birds have been tracked during more than 1 migratory journey. Currently, a large effort is being made to develop a satellite tracking system for small animals, to be used in following up small passerines on migration (Wikelski et al. 2007). The continuous registration of complete migratory journeys holds great promise, not only for providing new insights into the consistency and variation of individual migration, but also for identifying the environmental factors that contribute to this variation. If, for each individual bird, the location at a particular time can be identified, the environmental conditions at that very time can be considered for the interpretation of stopover strategies, migration speed, or the use of particular flight routes.

An alternative method that has been successfully applied to identify the location and quality of wintering sites and migration routes is the determination of stable isotope profiles from animal tissues that are regularly renewed (e.g. claws, feathers, blood; see Hobson 2003, Bearhop et al. 2004, 2005, Mazerolle \& Hobson 2007). These isotope profiles mirror the ratio of isotopes in the area where tissues were grown and can, therefore, be used to determine the whereabouts of an individual bird at the particular time when these tissues were grown. The spatial resolution obtained by this method very much depends on the geographic variation of stable isotopes and the steepness of clines in isotope ratios. An advantage of this method as compared to ringing is that a bird does not need to be retrapped, which makes it possible to obtain information on the location of wintering sites and migration routes from a large number of individuals, including small birds with low recovery rates (Hobson 2003). In the future, the application of this method in groups of genetically related individuals (e.g. full sibs or parents and their offspring) will make it possible to assess phenotypic and genetic variation in the location of the wintering site, migration route and migration speed.

\subsection{Heritability: a measure of genetic variation}

A prerequisite for evolutionary change is the presence of additive genetic variation, i.e. that phenotypic variation is transmitted from one generation to the other. In the simplest of all quantitative genetic models (i.e. the breeder's equation; Falconer \& Mackay 1996) evolutionary change in trait means $(\Delta Z)$ is determined by the heritability $\left(h^{2}\right)$, i.e. the amount of additive genetic variance $\left(V_{\mathrm{a}}\right)$ standardized by total phenotypic variance $\left(h^{2}=V_{\mathrm{a}} / V_{\mathrm{P}}\right)$, and the strength of selection $(S)$. The rate of expected evolutionary change can be derived directly from the breeder's equation $\Delta Z=h^{2} S$. The heritability of a trait can be estimated from the resemblances (covariance) of trait expression in related individuals, i.e. individuals that share genes, as compared to the resemblance between unrelated individuals. Thereby, it is assumed that trait resemblances in related individuals are due to genetic resemblance. In most cases, however, close relatives, like full sibs, have more in common than their genes: they normally are raised and live in the same environment. This will bias most heritability estimates unless environmentally induced resemblance is negligible or taken into account (see Pulido \& Berthold 2003).

Heritability estimates for spring arrival and for traits that determine spring arrival, like timing of departure from the wintering grounds, have been obtained for only 4 species and are generally based on small sample sizes (Table 2). Mean heritability of these traits is 0.43 ( $\mathrm{SD}=0.38)$, which is similar to the estimate obtained for all migration phenologies studied so far, i.e. including autumn migration timing $\left(h^{2}=0.34, \mathrm{SD}=0.24, \mathrm{n}=\right.$ 12; see Pulido 2007). In principle, heritability estimates are only valid for the populations in which they are measured and only under the given environmental circumstances. Yet, some generalizations can be made about the evolvability of particular traits based on a few estimates (including those obtained under laboratory conditions) if genotype-by-environment interactions are relatively small, as seems to be the case

Table 2. Heritability estimates of spring arrival (Arr) and traits related to the timing of spring migration (Oma: onset of migratory restlessness in spring; Dep: departure from wintering ground) derived from wild birds (field) or birds kept under controlled conditions (lab). N: number of families. Significance levels: ${ }^{\mathrm{ns}} \mathrm{p}>0.05,{ }^{* *} \mathrm{p}<0.01$

\begin{tabular}{|c|c|c|c|c|c|c|}
\hline Trait & Species & Population & $\mathrm{N}$ & Heritability & Population & Source \\
\hline Oma & Sylvia borin & Switzerland (mountain) ${ }^{\mathrm{a}}$ & 15 & $0.78^{* *}$ & Lab & Widmer (1999) \\
\hline Oma & Sylvia borin & Germany (lowland) $^{\mathrm{a}}$ & 15 & $1.02^{* *}$ & Lab & Widmer (1999) \\
\hline Arr & Ficedula hypoleuca & Spain & 22 & $-0.50 / 0.34^{\mathrm{ns}}$ & Field & Potti (1998) ${ }^{b}$ \\
\hline Arr & Hirundo rustica & Denmark & 98 & $0.54^{* *}$ & Field & Møller (2001) \\
\hline Dep & Cygnus bewickii & UK & 31 & $0.10^{\mathrm{ns}}$ & Field & Rees (1989) \\
\hline
\end{tabular}


for migratory traits (see Pulido \& Berthold 2003 for a detailed discussion). So far, no study has experimentally tested the validity of heritabilities for spring migration timing. For the timing of autumn migration, however, we have a good idea of how estimates of genetic variation translate into evolutionary change. In a German blackcap population studied between 1988 and 1999, heritability of the onset of autumn migratory activity, i.e. the trait that determines departure from the breeding grounds, was determined for 11 different cohorts (Pulido et al. 2001a). Mean heritability estimates ranged between 0.34 and 0.45 . Using the breeder's equation and a conservative heritability estimate of 0.3, Pulido et al. (2001a) predicted a delay of the mean onset of migratory activity by 1 wk in 6 generations, i.e. in about 10 to $12 \mathrm{yr}$, under a moderate selection intensity of 0.35 , i.e. allowing $80 \%$ of the population with the latest onset of migratory activity to reproduce. Predictions from the breeder's equation were confirmed in an artificial selection experiment. Under strong artificial selection a significant delay of the onset of autumn migratory activity by $>1$ wk was achieved in 2 generations. Considering that heritabilities and coefficients of phenotypic variation for the onset of spring migratory activity are of equal magnitude (see Pulido \& Berthold 2003), we should expect similar rates of evolutionary change.

Theoretical and empirical studies predict and demonstrate that the amount of phenotypic, environmental and additive genetic variation should vary among trait classes (Merilä \& Sheldon 1999). Consequently, we need to distinguish between the different traits that determine spring arrival, such as the location of the wintering area, the timing of departure from the wintering grounds, migration route, migration speed and timing of settlement at the nesting site (Gordo 2007). These traits are likely to differ in complexity, control and selection regime, and their impact on spring arrival (Hedenström et al. 2007, this issue). Variation in arrival date is an integration of variation in these traits. Drawing on what we know about the circannual organisation of birds and its control, we should expect the timing of departure to be most insensitive to environmental variation, particularly in long-distance migrants (Berthold 1996, Coppack \& Both 2002, Pulido \& Widmer 2005), and, therefore, to have the highest heritability, yet environment-induced variation in physical condition may be an important source of phenotypic variation in departure date (Saino et al. 2007, Studds \& Marra 2007, both this issue; see also Section 4). Migration speed has been shown to vary considerably from year to year, and may very much depend on local environmental conditions; but it is not clear to what extent this is due to individual plasticity or whether this reflects fluctuations in the genetic composition of the population, for instance, as a consequence of amongyear variation in the survival of juveniles (see Møller \& Merilä 2004, Møller \& Szép 2005). Moreover, for predicting the potential for adaptive change, we need to clearly define and delimit the traits we are studying (van Noordwijk et al. 2006). For instance, changes in travel time may have multiple causes: change in flight speed (in response to wind conditions), in departure or stopover times, or in migration routes. All of these traits will be controlled by different sets of genes, and environmental and genetic variation among traits may differ. Arrival date is the most complex trait and the least amenable to genetic analysis, as variation in any of the traits preceding arrival will cause variation in arrival date. Thus, if we want to understand why individuals differ in arrival date, or why they arrive at the same time (Gunnarsson et al. 2004), we need to investigate how variation in wintering areas, departure times, migration routes, travelling speed, and finally territory establishment results in differences in arrival date.

Large variation in published heritability estimates of migration timing (see Table 2) is certainly not only due to the heterogeneity of traits studied and different levels of expected genetic variation, but also a consequence of the methodological difficulties of obtaining reliable estimates for individual arrival and departure dates (Pulido \& Berthold 2003, van Noordwijk et al. 2006; see Section 2.2). In addition, many published heritability estimates, particularly those obtained in the wild, will be inflated by common-environment and condition effects (see Section 4). New statistical techniques, like 'animal models' (Kruuk 2004, Postma \& Charmantier 2007) could help minimizing these effects, but the large pedigrees comprising several generations that would be required to follow such an approach are not yet available for the study of migratory behaviour in the wild.

\subsection{Genetic correlations}

Under selection, the rate and direction of phenotypic changes are not only determined by the additive genetic variation of a trait and the strength of selection on this trait, but also by selection on other traits to which the focal trait is genetically linked. Genetic correlations are, therefore, important determinants of evolutionary trajectories (Price \& Langen 1992, Arnold 1994, Falconer \& Mackay 1996, Etterson \& Shaw 2001). Migratory traits, particularly those that are related to the timing of migration, are expected to be tightly linked to other migratory traits and to traits of the annual life cycle (Pulido \& Berthold 1998, 2003, Pulido 2007). Estimates of genetic correlations for migratory traits are scarce and limited to experimental work on 
the blackcap, and to autumn migration in particular (Pulido et al. 1996, Pulido \& Berthold 1998, 2003). These studies demonstrate that migratory traits such as the timing, amount and incidence of migratory activity are tightly genetically correlated. The signs of genetic correlations are in accord with the expected direction of adaptive change with increasing or decreasing ambient temperatures (Pulido \& Berthold 1998, 2003). Selection for residency, for instance, will not only select for a higher proportion of resident birds, but also favour shorter migration distance and later departure from the breeding grounds as a consequence of high genetic correlations among these traits (Pulido et al. 1996). If selection is driving changes in multiple traits simultaneously, as we expect under a global-warming scenario, then the net selection intensity on each individual trait, and ultimately, selection response, will be much higher than without genetic covariation among traits (Pulido \& Berthold 2003, 2004). The genetic integration of seasonal events of the annual cycle and of the migratory syndrome may facilitate rapid adaptive changes of these complex physiological and behavioural processes without jeopardizing their functionality (Pulido 2007).

Genetic correlations of migratory traits with other life-cycle stages have been hitherto little explored. So far, there has only been a single study with blackcaps that experimentally investigated correlations between the timing of autumn migration and post-juvenile moult. A strong negative genetic correlation between migration onset and the time-lag between the end of juvenile moult and the onset of migration, as found in this study, suggests that no advancement in the onset of autumn migratory activity would ensue from selection favouring earlier termination of moult (Pulido \& Coppack 2004). This may become a constraint in adaptive evolution towards earlier departure from the breeding grounds. Another potential constraint in the adaptation of avian phenologies to the global increase in temperature is the tight correlation between hatching date and the timing of juvenile moult and migra- tion (Coppack et al. 2001, Pulido et al. 2001b). If the breeding season is advanced, chicks will hatch earlier in the season, which will result in earlier migration. This may or may not be adaptive. However, a persistent advancement of the breeding season is very likely to result in unseasonably early migration of the offspring, which may constrain a further advancement of the timing of reproduction (Coppack et al. 2001). The sign and strength of this correlation between hatching date and the onset of autumn migration, which reflects the rigidity of the juvenile developmental program, could change if selection favours a negative correlation between these 2 traits (Pulido et al. 2001b, Coppack \& Pulido 2004).

We currently have no information about genetic associations between spring migratory activity and other life history traits, though we expect these associations to be of the same importance as for autumn migration. Phenotypic correlations in a number of species (see Table 3), however, may give us an idea about the flexibility and constraints of the endogenous timeprogram controlling the timing of seasonal events in winter and spring. Limitations in the potential for advancing the timing of moult, which is tightly linked to the timing of migration (Table 3), have been suggested as constraints on the advancement of spring migration (Møller 2002, Drent 2006). Phenotypic covariances may to some extent reflect genetic variation (see discussion in Pulido \& Berthold 2003), yet much of this covariation could result from environmental variation affecting suites of traits, which may be due to the condition dependence of many life-history traits. For instance, variation in the timing of prenuptial moult and variation in spring arrival may both result from variation in ecological conditions experienced in winter that determine the physical condition of individual birds (Studds \& Marra 2007). Differences in physical condition will cause variation in the duration and timing of moult, which will then, as a carry-over effect, influence departure times and finally arrival times and reproductive success (Norris et al. 2004; see Section 4).

Table 3. Phenotypic correlations between spring migration and other life history traits. Dis: migratory disposition, Dep: departure from wintering ground, Oma: onset of migratory activity, Arr: arrival at breeding ground. Significance levels: ${ }^{\mathrm{ns}} \mathrm{p}>0.05,{ }^{*} \mathrm{p}<0.05$, ${ }^{* *} \mathrm{p}<0.01,{ }^{* * *} \mathrm{p}<0.001$

\begin{tabular}{|lllll|}
\hline Migratory trait & Life-history trait & Species & Correlation & \multicolumn{1}{c|}{ Source } \\
\hline Dis & Timing of gonadal development & Turdus merula & 0.52 to $0.54^{* *}$ & Partecke \& Gwinner (2007) \\
Dep & Arrival at wintering site & Cygnus columbianus & $-0.36^{* *}$ & Rees (1989) \\
Oma & End of autumn migratory activity & Sylvia borin & $0.64^{* *}$ & F. Pulido \& M. Widmer (unpubl.) \\
Oma & Onset of prenuptial moult & Sylvia borin & $0.48^{*}$ & F. Pulido \& M. Widmer (unpubl.) \\
Oma & End of prenuptial moult & Sylvia borin & 0.65 to 0.70*** Coppack (2002) \\
Arr & Migration duration & Anser caerulescens & $0.81^{* * *}$ & Bêty et al. (2004) \\
Arr & Departure from wintering area & Anser caerulescens & $0.14^{\text {ns }}$ & Bêty et al. (2004) \\
\hline
\end{tabular}




\subsection{Fitness difference among individuals arriving at different times}

If evolutionary changes in migration timing are currently taking place, we should expect to find fitness differences among individuals arriving at the breeding grounds at different times, and changes in these fitness differences with changes in the environment. In most bird populations, early breeding is associated with higher reproductive success, though there may be a trade-off between fitness of the offspring and survival of the parents (Drent 2006). Early arrival bears the cost of increased mortality due to a high probability of encountering inclement weather conditions very early in the season (Brown \& Brown 2000, Newton 2007). Males arriving early have a higher chance of settling in the best territories and obtaining a mate. This becomes particularly apparent in populations with a high proportion of so-called floaters, i.e. individuals that are present in the population but forgo breeding. The probability of a male remaining unmated increases the later it arrives (Møller 1994, Aebischer et al. 1996, Lozano et al. 1996, Currie et al. 2000, Amrhein et al. 2007, Ely et al. 2007). Moreover, in those males that find a mate, but also in females, early arrival increases reproductive success by allowing earlier breeding and by increasing the likelihood of successfully producing a replacement or second clutch (Møller 1994, 2002). In many bird species, arrival date is correlated with egg laying and hatching date (Tryjanowski et al. 2004, Smith \& Moore 2005, Ely et al. 2007). Earlier breeders produce larger clutches and have a higher number of chicks that are in better condition at fledging (Møller 1994). As a consequence, individuals born early in the season have higher survival probabilities and are more likely to recruit into the population (Drent 2006).

Currently there are only a few studies that link changes in the timing of breeding to fitness, and investigate changes in fitness over time in populations of migratory birds (Both \& Visser 2001, Sanz et al. 2003, Sheldon et al. 2003, Møller et al. 2006). Møller (2007) studied selection for the timing of arrival in barn swallows Hirundo rustica. All of these studies found selection for earlier breeding or arrival, as determined by the number of recruiting offspring. In pied flycatchers (Both \& Visser 2001, Sanz et al. 2003), male barn swallows (Møller 2007) and arctic terns Sterna paradisaea (Møller et al. 2006), there is a temporal trend for increased selection for earlier laying/arrival, indicating that the mismatch between the optimal and actual arrival or laying date has been increasing over time. Using an 'animal model', Sheldon et al. (2003) showed that in collared flycatchers Ficedula albicollis breeding on Gotland, environmen- tal deviation in laying date is strongly influenced by the NAO, which may mimic evolutionary change. If this effect is removed, there is no evidence for a change in laying date. Another problem, in some of these studies, is that fitness is measured as the probability of young hatched at different times of the season to recruit into the population. This measure of fitness, however, may not accurately consider all selection effects, like the probability of obtaining a mate, the mortality of parental birds after arrival but before breeding, and the survival probability and the change in condition of the parents (particularly of the mother) from one breeding season to the next. If viability selection is taken into account, the advantage of breeding early may become diminished (Sheldon et al. 2003) and the dynamics over time may change (Møller 2007). More complex models of optimal arrival time demonstrate that changes in arrival time do not necessarily follow the change in food availability (Jonzén et al. 2007a).

\subsection{Evolutionary change}

\subsubsection{Changes in spring arrival}

Despite a large body of evidence indicating that diverse components of avian migration, such as migration propensity, migration timing, migration distance and routes are changing in response to changes in climate (see reviews by Berthold 1998, Fiedler 2003, Fiedler et al. 2004, Lehikoinen et al. 2004), there are only few studies that were able to demonstrate evolutionary change in avian migratory behaviour (Pulido \& Berthold 2004, Pulido 2006, Gienapp et al. 2007). Currently, the most compelling evidence for evolutionary change in migration timing is provided by a study in cliff swallows Pterochelidon pyrrhonota breeding in Central North America. In 1996, an exceptionally long cold period in early spring killed a large proportion of birds that were present on the breeding grounds at that time, i.e. the swallows that had arrived early. In the following years, cliff swallows arrived at their colonies significantly later, as the birds that had survived this cold spell were those individuals that had arrived late in that year (Brown \& Brown 2000). Thus, there is strong evidence for directional viability selection for late arrival time caused by a cold spell in spring. Irregular, but recurrent, extreme weather events in spring may explain why, in this cliff swallow population, like in many other bird populations, often no long-term changes in arrival or breeding dates are found despite persistent and strong selection for early arrival and breeding in 'normal years' (see also Newton 2007). 


\subsubsection{Changes in wintering area}

Evidence for evolutionary shifts of wintering ranges comes from blackcaps that have recently started wintering in Ireland and the British Isles (Berthold et al. 1992). This evolutionary change involved shifts in migration direction, migration distance and in the timing of migration. Migration distance in these blackcaps wintering in the north is shorter than for blackcaps migrating to the traditional wintering areas around the south-western Mediterranean. As a consequence, they arrive significantly earlier in spring and start breeding earlier (Bearhop et al. 2005). But the main reason for their advancement in spring is that their circannual rhythm is accelerated by the photoperiodic conditions in the north (Terrill \& Berthold 1990, Coppack \& Pulido 2004). At the beginning of this process, i.e. 40 to $50 \mathrm{yr}$ ago, selection was probably driven by higher survival of birds wintering in the north, as a consequence of winter-feeding by humans (cf. Berthold \& Terrill 1988). In the last 2 decades, however, higher temperatures at the wintering grounds and earlier springs in the breeding areas in Central Europe have been increasing the fitness advantage of blackcaps migrating to northwestern Europe. As a consequence, and because of assortative mating for arrival date, this population of blackcaps is very rapidly increasing (Bearhop et al. 2005). From this example of evolutionary change in migratory behaviour in the blackcap we can learn two things. (1) Considerable evolutionary change can take place in a short period of time-here, in about 15 to 20 generations - as a consequence of moderate viability and fertility selection, and strong assortative mating. (2) Phenotypic changes can be larger than genetic shifts if the response to altered environmental conditions - here, the photoperiodic regime - is in the same direction as the evolutionary response (i.e. co-gradient variation).

Rapid changes in arrival times, as demonstrated in the blackcap, are expected to occur whenever there is a latitudinal shift in the wintering area (Coppack \& Pulido 2004). Therefore, it is likely that the latitudinal shift of the wintering area following a shortening of migration distance will be a central mechanism to modify the timing of spring arrival. Several lines of evidence support this hypothesis. (1) There is a positive correlation between migration distance and spring arrival, both within and among species (Lehikoinen et al. 2004, Mazerolle \& Hobson 2007). This may indicate that this is a major axis of evolutionary change, possibly favoured by negative genetic covariation between migration distance and the timing of spring migration (see Section 2.4 and Table 3). (2) Most populations of birds studied so far show high levels genetic variation for the amount of migratory activity, as indicated by moderate heritability and high phenotypic variation (Pulido \& Berthold 2003). This allows rapid changes in migration distance (Berthold \& Pulido 1994). (3) Recent northward shifts in wintering areas have been reported in numerous bird species (Burton 1995, Berthold 1998, Wernham et al. 2002, Fiedler 2003, Valiela \& Bowen 2003, BöhningGaese \& Lemoine 2004). (4) A large-scale commongarden experiment revealed that in a southern German blackcap population there has been considerable genetic change towards shorter migration distances between 1988 and 2001. At the same time, spring arrival has advanced in this population, probably as a correlated selection response (F. Pulido \& P. Berthold unpubl. data). (5) Northward shifts of the wintering area will result in earlier prenuptial moult, earlier onset of spring migratory activity and earlier gonadal development as a result of the physiological response to altered photoperiodic conditions experienced during winter and spring (Coppack et al. 2003, Coppack \& Pulido 2004).

Yet, although shortening of migration distance is probably one of the fastest means to change the timing of spring migration, it may not be possible for all migratory species to realize it. Species that cross large ecological barriers areas on migration, like most longdistance migrants, will be limited in their potential to shorten migration distance, particularly if they winter close to these barriers (e.g. trans-Saharan migrants wintering in the Sahel). These areas of unsuitable wintering habitat may prevent an evolutionary (gradual) shift of the wintering areas towards the breeding area (Pulido et al. 1996). Unfortunately, the demonstration of changes in migration distance based on ringing recoveries is very difficult, as mean recovery distances usually have large sampling errors (Wernham et al. 2002, Fiedler et al. 2004). Nevertheless, it will be worth an effort to test this hypothesis in species with large numbers of recoveries.

\subsubsection{Changes in timing of departure from wintering area}

Another way of responding to selection for earlier arrival on the breeding grounds is the evolutionary change of the timing of departure from the wintering areas. As in long-distance migrants the onset of migratory activity is primarily determined by an endogenous circannual programme that is modified by changes in daylength (Berthold 1996, Gwinner 1996), it has been suggested that an evolutionary change in arrival time in this group of birds would require an evolutionary change in the response to the photoperiod (Both \& Visser 2001, Coppack \& Both 2002). Considering the 
presence of significant additive genetic variation in the onset of spring migratory activity, which has been demonstrated for 2 garden warbler populations (Widmer 1999) and a pied flycatcher population (F. Pulido, C. Both \& M. E. Visser unpubl. data), and the intraspecific genetic among-population differentiation in the response to the photoperiod in garden warblers (Widmer 1999), an evolutionary shift in the onset of spring migration through a change of the response threshold to daylength does not seem unlikely.

A recent analysis of long-term trapping patterns at 1 station in Italy and 5 observatories in Scandinavia found that most species of long-distance migrants significantly advanced their spring passage through southern Italy in the period from 1980 to 2004 (Jonzén et al. 2006). This advancement was similarly strong at the Scandinavian sites, i.e. close to the presumed breeding sites of these species. The fact that birds arrive significantly earlier at a site located just after crossing 2 large ecological barriers, the Sahara and the Mediterranean Sea, suggests that the advancement of arrival observed in northern Europe is not due to an environment-induced acceleration of migration through Europe, but to an advancement of migration from the wintering site. Ruling out that environmental conditions in Africa may have induced earlier departure, Jonzén et al. (2006, 2007b) suggested that the observed patterns could be 'due to climate-driven evolutionary changes in the timing of spring migration' (Jonzén et al. 2006, p. 1960). The aforementioned study may provide circumstantial evidence for evolutionary changes in departure dates, but a number of the assumptions made by the authors, like the constancy and homogeneity of the composition of the population migrating through southern Italy, are not without problems (Both 2007). A clear demonstration of evolutionary change will require controlled experiments and/or a long-term population study with high recruitment rates and site fidelity of birds that would allow quantitative genetic analyses of departure and arrival dates (see Pulido \& Berthold 2004).

\subsubsection{Changes in migration speed}

It is currently unclear if and how evolutionary changes in migration speed take place. In view of the strong impact of weather and physical condition on travelling time (see Sections $3.1 \& 4$ ), we would expect evolutionary changes in the physiological response to the climatic variables that influence stopover propensity and duration, and fuelling rates (Jenni \& Schaub 2003). However, as we currently have no information as to what extent heritable genetic differences among individuals contribute to the observed phenotypic variation, we can only speculate on the importance of evolutionary changes in migration speed for the adaptation of arrival time. The large among-year variation in travelling time and routes found in a few individuals of large soaring birds, like storks and eagles, suggests that migration time, and the traits determining it, could be very flexible and probably have small heritabilities (see Section 2.2). However, our knowledge of exact migration routes and strategies is limited to a few individuals of large species that have long generation times and in which migration habits are predominantly culturally transmitted. In these species, trajectories of adaptive evolution may considerably differ from those in other groups of birds (Sutherland 1998, van Noordwijk et al. 2006, Pulido 2007).

\section{ENVIRONMENT-INDUCED CHANGES IN SPRING MIGRATION}

\subsection{The influence of weather on bird migration}

Many recent studies that reported changes in the phenology of spring migration in birds have attributed these changes to phenotypic plasticity in response to environmental alterations (Sokolov et al. 1998, Hüppop \& Hüppop 2003, Sokolov \& Kosarev 2003, Ahola et al. 2004, Anthes 2004, Vähätalo et al. 2004, Stervander et al. 2005, Croxton et al. 2006, Hüppop \& Winkel 2006, Both \& te Marvelde 2007, Saino et al. 2007, Sinelschikova et al. 2007). This inference is based on the finding that among-year variation in the timing of spring migration is correlated with local temperatures, temperatures en route, or temperatures or precipitation at the wintering grounds, or to global climatic indices like the NAO, the ENSO (El Niño Southern Oscillation), or the NDVI (Normalized Difference Vegetation Index) of a particular area (reviewed by Lehikoinen et al. 2004, Gordo 2007). One problem with these studies is that they report and interpret correlations of weather variables with migration timing without testing alternative hypotheses. Thus, it is not clear whether the studied variables are indeed the most important factors affecting the timing of migration (but see Forchhammer et al. 2002). Moreover, correlational studies cannot demonstrate causation. It has been hypothesized that earlier migration with higher temperatures en route results from higher migration speed as a consequence of earlier vegetation development, earlier appearance of food resources (e.g. insects), or a higher frequency and strength of tailwinds (Hüppop \& Hüppop 2003, Marra et al. 2005, Croxton et al. 2006, Hüppop \& Winkel 2006, Zalakevicius et al. 2006, Sinelschikova et al. 2007, Gordo 
2007). Any of these explanations, however, would suggest that among-year variation in arrival date is not due to phenotypic plasticity in an evolutionary sense, but is due rather to among-year or among-site variation in environmental conditions favouring or constraining migratory flight. It is not at all clear whether variation in response to these conditions is due to genetic differences among individuals, or whether it is due to differences in the conditions to which individuals are exposed. A recent study on breeding times in guillemots Uria aalge demonstrated, for instance, that, despite large among-population variation in response to the NAO, individuals within a population showed a very similar response (Reed et al. 2006), suggesting that environmental variation is the cause of phenotypic differences among individuals. In contrast to this, Brommer et al. (2005) found considerable among-individual variation in the response of laying date to spring temperature in collared flycatchers. In this population, additive genetic variation contributed significantly to variation in the intercept, but not to the slope of the response. In Dutch pied flycatchers, variation in the response of laying date to spring temperatures had a significant genetic component (Nussey et al. 2005).

It is well established that weather conditions have a major influence on the incidence and speed of avian migration, stopover duration and fuel deposition rate. This subject has been given thorough treatment in a number of original publications and reviews (see Richardson 1978, 1990, Berthold 1996, Schaub \& Jenni 2001, Jenni \& Schaub 2003). In a nutshell, migration speed is higher under favourable conditions, i.e. when temperatures are high or rising, the sky is clear, in the absence of rain or snow, and with tailwinds or in the absence of wind (reviewed by Richardson 1978, 1990, Elkins 1988, Berthold 1996). The direct effect of barometric pressure on the timing of spring migration is not clear, but it seems that migration movements are higher when air pressure is decreasing. Because temperature is intercorrelated with so many other weather variables like precipitation, cloudiness, fog, wind and freezing-but also with ecological factors like food availability, energy need, etc.-temperature effects are likely to be confounded with other effects (Richardson 1978, 1990). Wind speed and direction are probably the most important weather variables determining migration speed and migration patterns in many bird species (Barriocanal et al. 2002, Erni et al. 2002, 2005, Liechti 2006). A first study investigating the impact of changes in wind direction and strength on recent changes in the timing of spring passage found that the frequency of tailwind has increased in western and central Europe during the main migratory period of Baltic song thrushes Turdus philomelos, which is concordant with the migration period of many longdistance migrants breeding in central and northern Europe (Sinelschikova et al. 2007). Variation in mean passage of song thrushes was to a large extent explained by among-year variation in tailwind frequency and precipitation. Given the well-established impact of wind direction and speed on the incidence and speed of migratory movements, it is unclear why changes in wind conditions have not been considered in more studies investigating the causes of amongyear variation in bird migration timing. High correlations of migration phenology in spring with temperatures or with the NAO, as reported by many authors, do not eliminate the possibility that birds primarily respond to changes in wind speed and direction, as these are determined by differences in atmospheric pressure at different locations (Pryor \& Barthelmie 2003) and are correlated to the NAO (Hurrell \& Dickson 2004) and temperature variation (Pirazzoli \& Tomasin 2003). Moreover, wind conditions have changed significantly all over Europe (Keevallik 2003, Pirazzoli \& Tomasin 2003, Pirazzoli 2005). An increase of the winter NAO to more positive values, as observed in the last decades, is associated with an increase of the strength of westerly winds over northern Europe (Hurrell \& Dickson 2004), which may result in an increase of tailwinds for some migrants breeding in northern Europe and Siberia (see also Zalakevicius et al. 2006).

Among-species differences in migration periods, migration routes, and in the sensitivity of the response to weather, as found, for instance, between short- and long-distance migrants (Nilsson et al. 2006), could partly explain among-species variation in the rate of advancement of spring arrival in response to recent climate change. However, the large uncertainty of current projections of wind speed and frequency of wind directions under climate change scenarios (Pryor et al. 2006) will make the prediction of changes in wind conditions at a regional scale difficult, if not impossible. Thus, it is currently a very difficult task to attempt to predict future changes in the timing of migration based on these projections.

\subsection{Phenotypic plasticity}

'Phenotypic plasticity is the property of a given genotype to produce different phenotypes in response to distinct environmental conditions' (Pigliucci 2001, p. 1). The important role of phenotypic plasticity for the adaptation to new environmental conditions is increasingly being acknowledged (Thompson 1991, Price et al. 2003, Ghalambor et al. 2007, Gienapp et al. 2008, 
Hendry et al. 2008). One characteristic of phenotypic plasticity is that it is linked to a genotype (like any other phenotypic trait); if there is genetic variation for plasticity in a population, adaptive changes in plasticity are expected (Pigliucci 2001, Nussey et al. 2005, 2007).

\subsubsection{Response to daylength}

Daylength is the most important environmental factor modifying the expression of migratory behaviour. In spring, prenuptial moult, migratory activity and gonadal growth are accelerated if birds are exposed to long days (Gwinner 1986, 1996, Berthold 1996, Coppack \& Pulido 2004). However, at which daylength and by how much these seasonal events will be advanced may vary between populations, or between individuals within a population (Pulido \& Berthold 2003). Geographic variation in this photoperiodic response is adaptive, allowing birds to arrive at the breeding grounds and initiate breeding at the appropriate time (see Drent 2006, Jonzén et al. 2007a). Using daylength for the timing of departure from the wintering grounds is particularly important in long-distance migrants, as this group of birds does not have any information on the development of conditions at the breeding grounds (Coppack \& Both 2002, Coppack \& Pulido 2004). Currently there are 2 species for which genetic differences in the response of migration timing has been demonstrated. In southern German blackcaps, individuals from different families differ significantly in their response of the age at the onset of autumn migratory activity to variation in hatching date (Pulido 2000, Pulido et al. 2001b). Male and female garden warblers Sylvia borin from 2 populations differed in the response of the onset of spring migratory activity to 2 different photoperiodic regimes (constant light versus increasing daylength) to which they were exposed in spring (Widmer 1999).

\subsubsection{Response to temperature}

Experiments with common starlings Sturnus vulgaris and with different subspecies of white-crowned sparrows Zonotrichia leucophrys suggest that temperature changes in winter are not likely to have a major effect on the timing of gonadal maturation, particularly in male birds and, therefore, probably not on the timing of migration either (Wingfield et al. 1996, Dawson 2005). The sensitivity of the annual cycle to temperature, however, seems to be sex and species dependent and related to the flexibility of the breeding season. Females and species with a more flexible breeding season seem to be more responsive to changes in temperature (see Wingfield et al. 1992, 2003). And even in those species that show no or small temperature effects on the timing and rate of gonadal growth, high temperatures may cause an advancement of post-nuptial moult and gonadal regression, thereby shortening the reproductive season (Dawson 2005). Currently, it is unclear whether phenotypic plasticity in response to temperature plays an important role in the adaptation of life cycles to climatic changes, as we do not know whether temperature changes at the wintering grounds per se can induce earlier migration. Moreover, we do not know if birds respond directly to temperatures en route (see Cochran \& Wikelski 2005) or whether there is genetic variation in this response. Yet, there is generally no evidence that evolutionary response to rapid climate change involves changes in the physiological response to temperature (Bradshaw \& Holzapfel 2008). Common-garden and split-brood experiments using realistic temperature regimes to simulate conditions in the wild could help us to better understand the role of phenotypic plasticity of the response to temperature in the adaptation of spring life-cycle stages to climate change.

\subsubsection{Arrival date}

To date, the best evidence for phenotypic plasticity of arrival date in response to environmental variation is provided by a study in barn swallows. From 1993 through 2001, Saino et al. (2004a) studied year-to-year changes in the timing of arrival and breeding in individual barn swallows breeding in northern Italy. They showed that the NDVI, a measure of environmental condition in the wintering area of this population, was a strongly significant predictor of individual changes in arrival date. Under favourable conditions at the African wintering grounds, experienced individuals arrived earlier in their breeding areas in Italy. NDVI also affected laying date, but this effect was mediated by the effect of NDVI on arrival. In young birds (i.e. from their first to the second arrival at the breeding area), no such effect was found, probably because the timing of arrival in yearlings is more strongly determined by migration time than by departure date. Unfortunately, the authors did not study the effects of weather variables like temperature, precipitation, wind, or the NAO or NDVI in areas en route, which have been shown to be important predictors of variation in arrival and breeding date in many populations (Hüppop \& Hüppop 2003, Forchhammer et al. 2002, Sokolov \& Kosarev 2003, Anthes 2004, Vähätalo et al. 2004, Stervander et al. 2005, Both et al. 2006b, Zalake- 
vicius et al. 2006, Croxton et al. 2006, Sinelschikova et al. 2007), including barn swallows (Huin \& Sparks 1998, Møller 2004, Møller \& Szép 2005, but see Saino et al. 2007).

This study with the barn swallows (Saino et al. 2004a) is currently the only longitudinal analysis of individual plasticity in spring arrival. Yet any population study that monitors arrival in spring and that has sufficient numbers of individuals returning to the breeding sites in more than $1 \mathrm{yr}$ (see Table 1) could be used to conduct similar analyses. Interesting questions to be addressed in such studies, particularly if it is possible to do this for different species and populations, would be (1) Is the individual response to an environmental variable uniform within a population or is there variation between individuals (i.e. individual-by-environment interaction)? (2) What is the range of environmental fluctuations (e.g. timing of spring) to which individuals show an adaptive response? (3) Is there inter- and intraspecific variation in the strength and direction of response to weather variables? (4) Do populations and species differ in the environmental variables to which they respond adaptively?

In addition to solid field data, split-brood experiments in which environmental conditions are controlled would help to address these questions (van Noordwijk et al. 2006). This experimental approach is so powerful that conclusive results may be obtained even with moderate sample sizes (see Pulido \& Coppack 2004).

\section{PHYSICAL CONDITION AND CHANGES IN SPRING MIGRATION}

\subsection{Effects of body condition on migration timing}

While microevolution and phenotypic plasticity have been repeatedly discussed as potential mechanisms underlying phenotypic changes in migration phenology (Pulido \& Berthold 2004, Jonzén et al. 2006, 2007b, Both 2007, Gienapp et al. 2007), the effects of environment-induced variation in body condition have hitherto hardly been explored. Yet, there is strong empirical evidence that the physical condition of birds has a major influence on their migration timing. (1) Birds arriving early in the season are in better condition than those individuals arriving late (e.g. Møller 1994, 2001, Ninni et al. 2004), suggesting that being in good condition is a prerequisite for arriving early and breeding early (see examples in Newton 2006), but this may be confounded by differences in arrival and condition between age classes (Mitrus 2007). (2) Migrants wintering in good habitats are in better condition, leave the wintering sites, and arrive at the breeding grounds before birds wintering in suboptimal habitats (Marra \& Holmes 2001, Bearhop et al. 2004, Norris et al. 2004, Norris 2005, Saino et al. 2004a,b, 2007, Studds \& Marra 2005, 2007). (3) Birds born early in the season and raised in the best territories are in best condition when they leave the nest (e.g. high fledging weight, low number of parasites). As a consequence, they have the highest probability of survival and are, therefore, likely to occupy the best habitats in winter, which will facilitate the maintenance of good condition and early return to the breeding sites (Sternberg \& Grinkov 2006). Likewise, birds breeding early and in the best territories will occupy the best territories in winter and return earlier to the breeding grounds in the following breeding season (Gunnarsson et al. 2005).

In so-called 'capital breeders' (e.g. geese, swans and some duck species) that accumulate reserves on the wintering grounds and at stopover sites, which they then use for breeding (see Klaassen et al. 2006), a delay in breeding is expected if, due to mistiming or habitat deterioration, birds cannot accumulate sufficient reserves. Lesser scaups Aythya affinis breeding in Manitoba, for instance, have delayed nest initiation by 1 to $2 \mathrm{wk}$ within a period of about $30 \mathrm{yr}$. At the same time, a significant decrease in body mass, lipids and minerals was observed in the northern staging areas and upon arrival. This reduction in body reserves may have resulted in a clutch size reduction of 4 to 5 eggs (Anteau \& Afton 2004). Low reproductive success due to poor body condition on arrival is possibly the cause of the decline of this scaup population (Afton \& Anderson 2001). Thus, not only environmental conditions in the breeding or wintering areas may determine condition on arrival, but also food availability at stopover sites or wind conditions on migration (as headwinds increase the energetic cost of migration) may have a considerable influence on arrival date and, subsequently, on breeding success (Madsen 2001, Prop et al. 2003, see also reviews by Drent 2006, Newton 2006). Apparently physical condition at all stages of the annual cycle may affect the timing of migration in spring. The impact of variation in condition may be even more severe than we expect if we consider that condition effects are likely to be multiplied by carryover effects. If, for instance, poor condition causes females to delay breeding, their offspring will develop under sub-optimal conditions. Chicks from these late broods will hatch at a time when food abundance in general, and of the appropriate food for rearing chicks in particular, is low and declining. As a consequence, they will be in poor physical condition at fledging, which may then result in late arrival and/or arrival in poor condition at the wintering grounds. There, these birds are likely to settle in poor habitats, which will make it difficult for them to accumulate the fat reserves 
they need for migration and to start migration early (Studds \& Marra 2007). If these individuals survive and return to the breeding area in the following year, they will be in poor physical condition and will breed late. Likewise, parents reproducing late in the season have to work more to feed their young and may, therefore, as a carry-over effect of the poor condition after breeding, return to the breeding grounds later in the following year.

\subsection{Evolutionary consequences of condition dependence of migration timing}

If the food peak is constantly advancing, following an increase in spring temperatures, birds that reproduce too late will never be able to catch up as they will be mistimed, both because they are genetically late and because the mistiming initially resulted in poor physical conditions of both the breeding birds and their offspring. These late birds will then be late in following breeding seasons because of poor condition. Selection on these individuals will be stronger than we would expect from the difference of the optimal phenotype and the distribution of breeding values. Parents reproducing early in the season, i.e. matching the maximum need for food of their chicks with the food peak will be in better condition and arrive earlier in the following year, as will their offspring. Thus, condition effects will strongly impact the shape and direction of selection. In principle, earlier and later arrival in a population could be achieved only by the change in condition of birds. This, however, could be a serious problem for the detection and prediction of evolutionary change, as phenotypic changes will not only reflect genotypic changes, but will be masked by condition effects. If the evolutionary response to persistent directional selection (e.g. for earlier breeding and spring arrival) lags behind the change in selection we may face the situation that we observe no or little advancement of migration, or even a delay, while there is a genetic change (given that variation in arrival is not only determined by condition). This has been found repeatedly in studies that have estimated changes in breeding values, i.e. genetic changes, and compared them with phenotypic changes, particularly in response to rapid anthropogenic alterations (see Merilä et al. 2001b, Gienapp et al. 2008).

\section{SUMMARY AND CONCLUSIONS}

The timing of avian spring migration is the phenological trait for which we have the largest body of data in animals. Yet, despite strong evidence for an advancement of spring passage and arrival, we still have very limited knowledge of the mechanisms underlying the phenotypic changes observed. Based on the presence of additive genetic variation and strong selection for earlier breeding, we expect evolutionary changes in the timing of spring migration, and selection for earlier breeding and arrival, is likely to increase if the trend for increasing temperatures persists. The most likely evolutionary processes leading to a change in migration timing are adaptive changes in migration distance and changes in phenotypic plasticity of departure date in response to daylength at the wintering grounds. Genetic correlations, particularly between the timing of breeding, moult and migration, are likely to be major determinants of evolutionary trajectories that could retard the evolution of the timing of these life-history stages to an optimum.

There is strong evidence for a direct effect of weather on the timing and propensity of migration. Therefore, it is very likely that the observed changes in migration phenologies are to a large extent induced by environmental changes in winter and spring conditions. Yet, it is not clear to which environmental variable(s) birds respond. A direct acceleration or deceleration of the speed of migration is expected in response to food availability at stopover sites, changes in wind conditions and changes in the frequency of adverse conditions with heavy precipitation. Whether temperature per se has a major effect on the timing of migration is currently unclear. Climatic indices like the NAO could directly affect migration timing through wind conditions and the availability of food. Unfortunately, the effects of changes in wind directions and speed, which may be important, have, so far, hardly been considered in the interpretation of phenological changes in migration. The physical condition of birds is a major determinant of departure time and, therefore, spring arrival. Positive feedback loops caused by carry-over effects may result in strong covariation between arrival date and condition, which may persist over several generations. These condition effects could mask evolutionary change, and, probably, also prevent it, by facilitating selection on the environmental deviation of phenotypic variation. As migratory birds are facing changes in food availability, for instance, due to temporal mismatches, habitat deterioration, or increased competition at all stages of their annual cycle, it is likely that under persistent climatic shifts birds will experience significant changes in physical condition. Monitoring these changes will prove crucial for being able to study their effects. Changes in condition could be a key factor for understanding the observed change in spring phenology.

In view of the lack of information on almost all aspects of the mechanistic causes of current pheno- 
typic changes in spring migration, it is difficult to highlight particular questions that should deserve more attention in the future. Yet, a number of important aspects, which I have outlined in this article, have been hitherto almost completely neglected, i.e. shifts in wintering ranges, the effects of changes in wind direction and speed, and the effects of changes in physical condition, and, in particular, the trans-generational carryover effects of poor condition (e.g. from one breeding season to the next). At the moment, we are starting to perceive the complexity of the phenomenon of changes in migration phenology and its potential causes, but we do not yet understand it. Intensive research, including powerful experimental approaches will be needed to identify the mechanisms underlying the currently observed changes in bird migration and to predict adaptive responses and their limitations.

Acknowledgements. I thank Marcel E. Visser, Arie J. van Noordwijk, Timothy Coppack and 5 anonymous reviewers for their critical comments that helped improve the manuscript.

\section{LITERATURE CITED}

Aebischer A, Perrin N, Krieg M, Studer J, Meyer DR (1996) The role of territory choice, mate choice and arrival date on breeding success in the Savi's warbler Locustella luscinioides. J Avian Biol 27:143-152

Afton AD, Anderson MG (2001) Declining scaup populations: a retrospective analysis of long-term population and harvest survey data. J Wildl Manage 65:781-796

Ahola M, Laaksonen T, Sippola K, Eeva T, Rainio K, Lehikoinen E (2004) Variation in climate warming along the migration route uncouples arrival and breeding dates. Glob Change Biol 10(9):1610-1617

Alerstam T, Hake M, Kjellen N (2006) Temporal and spatial patterns of repeated migratory journeys by ospreys. Anim Behav 71:555-566

Amrhein V, Kunc HP, Schmidt R, Naguib M (2007) Temporal patterns of territory settlement and detectability in mated and unmated nightingales Luscinia megarhynchos. Ibis 149:237-244

Anteau MJ, Afton AD (2004) Nutrient reserves of lesser scaup (Aythya affinis) during spring migration in the Mississippi flyway: a test of the spring condition hypothesis. Auk 121:917-929

Anthes N (2004) Long-distance migration timing of Tringa sandpipers adjusted to recent climate change. Bird Study 51:203-211

Arnold SJ (1994) Multivariate inheritance and evolution: a review of concepts. In: Boake CRB (ed) Quantitative genetic studies of behavioral evolution. University of Chicago Press, Chicago, IL, p 17-48

Barriocanal C, Montserrat D, Robson D (2002) Influences of wind flow on stopover decisions: the case of the reed warbler Acrocephalus scirpaceus in the western Mediterranean. Int J Biometeorol 46:192-196

Battley PF (2006) Consistent annual schedules in a migratory shorebird. Biol Lett 2:517-520

Bearhop S, Hilton GM, Votier SC, Waldron S (2004) Stable isotope ratios indicate that body condition in migrating passerines is influenced by winter habitat. Proc R Soc Lond B Biol Sci 271(Suppl):215-218

Bearhop S, Fiedler W, Furness RW, Votier SC and others (2005) Assortative mating as a mechanism for the rapid evolution of a migratory divide. Science 310:502-504

Berthold P (1995) Microevolutionary aspects of bird migration based on experimental result. Isr J Zool 41:377-385

Berthold P (1996) Control of bird migration. Chapman \& Hall, London

Berthold P (1998) Vogelwelt und Klima: gegenwärtige Veränderungen. Naturwiss Rundsch 51:337-346

Berthold P, Pulido F (1994) Heritability of migratory activity in a natural bird population. Proc R Soc Lond B Biol Sci 257:311-315

Berthold P, Terrill SB (1988) Migratory behaviour and population growth in blackcaps wintering in Britain and Ireland: some hypotheses. Ringing Migr 9:153-159

Berthold P, Helbig AJ, Mohr G, Querner U (1992) Rapid microevolution of migratory behaviour in a wild bird species. Nature 360:668-670

Berthold P, Fiedler W, Schlenker R, Querner U (1998) 25-year study of the population development of Central European songbirds: a general decline, most evident in longdistance migrants. Naturwissenschaften 85:350-353

Berthold P, von der Bossche W, Jakubiec Z, Kaatz C, Kaatz M, Querner U (2002) Long-term satellite tracking sheds light upon variable migration strategies of white storks (Ciconia ciconia). J Ornithol 143:489-493

Berthold P, Kaatz M, Querner U (2004) Long-term satellite tracking of white stork (Ciconia ciconia) migration: constancy versus variability. J Ornithol 145:356-359

Bertin A, Houdelier C, Richard-Yris MA, Guyomarc'h C, Lumineau S (2007) Stable individual profiles of daily timing of migratory restlessness in European quail. Chronobiol Int 24:253-267

Bêty J, Giroux JF, Gauthier G (2004) Individual variation in timing of migration: causes and reproductive consequences in greater snow geese (Anser caerulescens caerulescens). Behav Ecol Sociobiol 57:1-8

Boag PT, van Noordwijk AJ (1987) Quantitative genetics. In: Buckley PA, Cooke F (eds) Avian genetics. Academic Press, London, p 45-78

Böhning-Gaese K, Lemoine N (2004) Importance of climate change for the ranges, communities and conservation of birds. Adv Ecol Res 35:211-236

Both C (2007) Comment on 'Rapid advance of spring arrival dates in long-distance migratory birds'. Science 315:598b

Both C, te Marvelde L (2007) Climate change and timing of avian breeding and migration throughout Europe. Clim Res 35:93-105

Both C, Visser ME (2001) Adjustment to climate change is constrained by arrival date in a long distance migrant bird. Nature 411:296-298

Both C, Bouwhuis S, Lessells CM, Visser ME (2006a) Climate change and population declines in a long-distance migratory bird. Nature 441:81-83

Both C, Sanz JJ, Artemyev AA, Blaauw B and others (2006b) Pied flycatchers Ficedula hypoleuca travelling from Africa to breed in Europe: differential effects of winter and migration conditions on breeding date. Ardea 94:511-525

Bradshaw WE, Holzapfel CM (2008) Genetic response to rapid climate change: it's seasonal timing that matters. Mol Ecol 17:157-166

Bregnballe T, Frederiksen M, Gregersen J (2006) Effects of distance to wintering area on arrival date and breeding performance in great cormorants Phalcrocorax carbo. Ardea 94:619-630 
Brommer JE, Merilä J, Sheldon BC, Gustafsson L (2005) Natural selection and genetic variation for reproductive reaction norms in a wild bird population. Evolution 59: 1362-1371

Brown CR, Brown MB (2000) Weather-mediated natural selection on arrival time in cliff swallows (Petrochelidon pyrrhonota). Behav Ecol Sociobiol 47:339-345

Burton JF (1995) Birds and climate change. Christopher Helm, London

Cochran WW, Wikelski M (2005) Individual migratory tactics of New World Catharus thrushes: current knowledge and future tracking options from space. In: Greenberg $\mathrm{R}$, Marra P (eds) Birds of two worlds: ecology and evolution of migration. Johns Hopkins University Press, Baltimore, MD, p 274-289

Coppack T (2002) Photoperiodic responsiveness and life-cycle adaptability of Palaearctic-African passerine migrants with respect to global environmental change. Edition Wissenschaft, Reihe Biologie, Band 263, Tectum Verlag, Marburg

Coppack T, Both C (2002) Predicting life-cycle adaptation of migratory birds to global climate change. Ardea 90: 369-378

Coppack T, Pulido F (2004) Photoperiodic response and the adaptability of avian life-cycles to climate change. Adv Ecol Res 35:131-150

Coppack T, Pulido F, Berthold P (2001) Photoperiodic response to early hatching in a migratory bird species. Oecologia 128:181-186

Coppack T, Pulido F, Czisch M, Auer DP, Berthold P (2003) Photoperiodic response may facilitate adaptation to climatic change in migratory birds. Proc R Soc Lond B Biol Sci 270(Suppl):43-46

Croxton PJ, Sparks TH, Cade M, Loxton RG (2006) Trends and temperature effects in the arrival of spring migrants in Portland (United Kingdom) 1959-2005. Acta Ornithol (Wars) 41:103-111

Currie D, Thompson DBA, Burke T (2000) Patterns of territory settlement and consequences for breeding success in the northern wheatear Oenanthe oenanthe. Ibis 142: 389-398

Dawson A (2005) The effect of temperature on photoperiodically regulated gonadal maturation, regression and moult in starlings - potential consequences for climate change. Funct Ecol 19:995-1000

Drent RH (2006) The timing of birds' breeding seasons: the Perrins hypothesis revisited especially for migrants. Ardea 94:305-322

Elkins N (1988) Weather and bird behaviour. Poyser, Calton

Ely CR, Bollinger KS, Densmore RV, Rothe TC, Petrula MJ, Takekawa JY, Orthmeyer DL (2007) Reproductive strategies of northern geese: Why wait? Auk 124:594-605

Endler JA (1986) Natural selection in the wild. Princeton University Press, Princeton, NJ

Erni B, Liechti F, Underhill LG, Bruderer B (2002) Wind and rain govern the intensity of nocturnal bird migration in central Europe-A log-linear regression analysis. Ardea 90:155-166

Erni B, Liechti F, Bruderer B (2005) The role of wind in passerine autumn migration between Europe and Africa. Behav Ecol 16:732-740

Etterson JR, Shaw RG (2001) Constraint to adaptive evolution in response to global warming. Science 294:151-154

Falconer DS, Mackay TFC (1996) Introduction to quantitative genetics, 4th edn. Longman, Harlow

Fiedler W (2003) Recent changes in migratory behaviour of birds: a compilation of field observations and ringing data.
In: Berthold P, Gwinner E, Sonnenschein E (eds) Avian migration. Springer, Heidelberg, p 21-38

Fiedler W, Bairlein F, Köppen U (2004) Using large-scale data from ringed birds for the investigation of effects of climate change on migrating birds: pitfalls and prospects. Adv Ecol Res 35:49-67

Forchhammer MC, Post E, Stenseth NC (2002) North Atlantic Oscillation timing of long- and short-distance migration. J Anim Ecol 71:1002-1014

Forstmeier W (2002) Benefits of early arrival at breeding grounds vary between males. J Anim Ecol 71:1-9

Ghalambor CK, McKay JK, Carroll SP, Reznik DN (2007) Adaptive versus non-adaptive phenotypic plasticity for contemporary adaptation in new environments. Funct Ecol 21:394-407

Gienapp P, Leimu R, Merilä J (2007) Responses to climate change in avian migration time-microevolution versus phenotypic plasticity. Clim Res 35:25-35

Gienapp P, Teplitsky C, Alho JS, Mills JA, Merilä J (2008) Climate change and evolution: disentangling environmental and genetic response. Mol Ecol 17:167-178

Gordo O (2007) Why are bird-migration dates shifting? A review of weather and climate effects on avian migratory phenology. Clim Res 35:37-58

Gunnarsson TG, Gill JA, Sigurbjörnsson T, Sutherland WJ (2004) Arrival synchrony in migratory birds. Nature 431: 646

Gunnarsson TG, Gill JA, Newton J, Potts PM, Sutherland WJ (2005) Seasonal matching of habitat quality and fitness in a migratory bird. Proc R Soc Lond B Biol Sci 272: $2319-2323$

Gunnarsson TG, Gill JA, Atkinson PW, Gélinaud G and others (2006) Population-scale drivers of individual arrival times in migratory birds. J Anim Ecol 75:1119-1127

Gwinner E (1986) Circannual rhythms. Springer, Berlin

Gwinner E (1996) Circadian and circannual programmes in avian migration. J Exp Biol 199:39-48

Hagan JM, Lloyd-Evans TL, Atwood JL (1991) The relationship between latitude and the timing of spring migration of North American landbirds. Ornis Scand 22:129-136

Hairston NG, Ellner SP, Geber MA, Yoshida T, Fox JA (2005) Rapid evolution and the convergence of ecological and evolutionary time. Ecol Lett 8:1114-1127

Hedenström A, Barta Z, Helm B, Houston AI, McNamara JM, Jonzén N (2007) Migration speed and scheduling of annual events by migrating birds in relation to climate change. Clim Res 35:79-91

Hendry AP, Farrugia TJ, Kinnison MT (2008) Human influences on rates of phenotypic change in wild animal populations. Mol Ecol 17:20-29

Hobson KA (2003) Making migratory connections with stable isotopes. In: Berthold P, Gwinner E, Sonnenschein E (eds) Avian migration. Springer, Heidelberg, p 379-391

Hopp SL, Kirby A, Boone CA (1999) Banding returns, arrival pattern, and site fidelity of white-eyed vireos. Wilson Bull 11:46-55

Hötker H (2002) Arrival of pied avocets Recurvirostra avosetta at the breeding site: effects of winter quarters and consequences for reproductive success. Ardea 90:379-387

Huin N, Sparks TH (1998) Arrival and progression of the swallow Hirundo rustica through Britain. Bird Study 45: 361-370

Hüppop O, Hüppop K (2003) North Atlantic Oscillation and the timing of spring migration in birds. Proc R Soc Lond B Biol Sci 270:233-240

Hüppop O, Winkel W (2006) Climate change and timing of spring migration in the long-distance migrant Ficedula 
hypoleuca in central Europe: the role of spatially different temperature changes along migration routes. J Ornithol 147:344-353

Hurrell JW, Dickson RR (2004) Climate variability over the North Atlantic. In: Stenseth NC, Ottersen G, Hurrell JW, Belgrano A (eds) Marine ecosystems and climate variation - the North Atlantic. Oxford University Press, Oxford, p 15-31

Jenni L, Schaub M (2003) Behavioural and physiological reactions to environmental variation in bird migration: a review. In: Berthold P, Gwinner E, Sonnenschein E (eds) Avian migration. Springer, Heidelberg, p 156-171

Jetz W, Wilcove DS, Dobson AP (2007) Projected impacts of climate and land-use change on the global diversity of birds. PLoS Biol 5(6):e157

Jonzén N, Lindén A, Ergon T, Knudsen E and others (2006) Rapid advance of spring arrival dates in long-distance migratory birds. Science 312:1959-1961

Jonzén N, Hedenström A, Lundberg P (2007a) Climate change and the optimal arrival of migratory birds. Proc R Soc Lond B Biol Sci 274:269-274

Jonzén N, Lindén A, Ergon T, Knudsen E and others (2007b) Response to comment on 'Rapid advance of spring arrival dates in long-distance migratory birds'. Science 315:598c

Keevallik S (2003) Changes in spring weather conditions and atmospheric circulation in Estonia (1955-95). Int J Climatol 23:263-270

Kinnison MT, Hendry AP (2001) The pace of modern life. II. From rates of contemporary microevolution to pattern and process. Genetica 112-113:145-164

Klaassen M, Abraham KF, Jefferies RL, Vrtiska M (2006) Factors affecting the site of investment, and the reliance on savings for arctic breeders: the capital-income dichotomy revisited. Ardea 94:371-384

Kruuk LEB (2004) Estimating genetic parameters in natural populations using the 'animal model'. Philos Trans R Soc Lond B Biol Sci 359:873-890

Lehikoinen E, Sparks TH, Zalakevicius M (2004) Arrival and departure dates. Adv Ecol Res 35:1-31

Liechti F (2006) Birds: Blowin' by the wind? J Ornithol 147: 202-211

Lozano GA, Perrault S, Lemon RE (1996) Age, arrival date and reproductive success of male American redstarts Setophaga ruticilla. J Avian Biol 27:164-170

Madsen J (2001) Spring migration strategies in pink-footed geese Anser brachyrhynchus and consequences for spring fattening and fecundity. Ardea 89:43-55

Marra PP, Holmes RT (2001) Consequences of dominancemediated habitat segregation in a migrant passerine bird during the non-breeding season. Auk 118:92-104

Marra PP, Francis CM, Mulvihill RS, Moore FR (2005) The influence of climate on the timing and rate of spring bird migration. Oecologia 142:307-315

Mazerolle DF, Hobson KA (2007) Patterns of differential migration in white-throated sparrows evaluated with isotopic measurements of feathers. Can J Zool 85:413-420

Menzel A, Sparks TH, Estrella N, Koch E and others (2006) European phenological response to climate change matches the warming pattern. Glob Change Biol 12:1969-1976

Merilä J, Sheldon BC (1999) Genetic architecture of fitness and nonfitness traits: empirical patterns and development of ideas. Heredity 83:103-109

Merilä J, Sheldon BC, Kruuk LEB (2001a) Explaining stasis: microevolutionary studies in natural populations. Genetica 112-113:199-222

Merilä J, Kruuk LEB, Sheldon BC (2001b) Cryptic evolution in a wild bird population. Nature 412:76-79
Meyburg BU, Meyburg C, Bělka T, Šreibr O, Vrana J (2004) Migration, wintering and breeding of a lesser spotted eagle (Aquila pomarina) from Slovakia tracked by satellite. J Ornithol 145:1-7

Mitrus C (2007) Is the later arrival of young male red-breasted flycatchers (Ficedula parva) related to their physical condition? J Ornithol 148:53-58

Møller AP (1994) Phenotype-dependent arrival time and its consequences in a migratory bird. Behav Ecol Sociobiol 35:115-122

Møller AP (2001) Heritability of arrival date in a migratory bird. Proc R Soc Lond B Biol Sci 268:203-206

Møller AP (2002) North Atlantic Oscillation (NAO) effects of climate on the relative importance of first and second clutches in a migratory passerine bird. J Anim Ecol 71: 201-210

Møller AP (2004) Protandry, sexual selection and climate change. Glob Change Biol 10:2028-2035

Møller AP (2007) Tardy females, impatient males: protandry and divergent selection on arrival date in the two sexes of the barn swallow. Behav Ecol Sociobiol 61:1311-1319

Møller AP, Merilä J (2004) Analysis and interpretation of longterm studies investigating responses to climate change. Adv Ecol Res 35:111-130

Møller AP, Szép T (2005) Rapid evolutionary change in a secondary sexual character linked to climatic change. J Evol Biol 18:481-495

Møller AP, Flensted-Jensen E, Mardal W (2006) Rapidly advancing laying date in a seabird and the changing advantage of early reproduction. J Anim Ecol 75:657-665

Morbey YE, Ydenberg RC (2001) Protandrous arrival timing to breeding areas: a review. Ecol Lett 4:663-673

Newton I (2006) Can conditions experienced during migration limit the population levels of birds? J Ornithol 147: $146-166$

Newton I (2007) Weather-related mass-mortality events in migrants. Ibis 149:453-467

Nilsson ALK, Alerstam T, Nilsson JÅ (2006) Do partial and regular migrants differ in their responses to weather? Auk 123:537-547

Ninni P, de Lope F, Saino N, Hussy C, Møller AP (2004) Antioxidants and condition-dependence of arrival date in a migratory passerine. Oikos 105:55-64

Norris DR (2005) Carry-over effects and habitat quality in migratory populations. Oikos 109:178-186

Norris DR, Marra PP, Kyser TK, Sherry TW, Ratcliffe LM (2004) Tropical winter habitat limits reproductive success on the temperate breeding grounds in a migratory bird. Proc R Soc Lond B Biol Sci 271:59-64

Nussey DH, Postma E, Gienapp P, Visser ME (2005) Selection on heritable phenotypic plasticity in a wild bird population. Science 310:304-306

Nussey DH, Wilson AJ, Brommer JE (2007) The evolutionary ecology of individual phenotypic plasticity in wild populations. J Evol Biol 20:831-844

Parmesan C (2006) Ecological and evolutionary response to recent climate change. Annu Rev Ecol Evol Syst 37: $637-669$

Parmesan C, Yohe G (2003) A globally coherent fingerprint of climate change impacts across natural systems. Nature 421:37-42

Parry ML, Canziani OF, Palutikof JP, van der Linden PJ, Hanson CE (eds) (2007) Climate Change 2007: impacts, adaptation and vulnerability. Contribution of Working Group II to the Fourth Assessment Report of the Intergovernmental Panel on Climate Change. Cambridge University Press, Cambridge 
Partecke J, Gwinner E (2007) Increased sedentariness in European blackbirds following urbanization: A consequence of local adaptation? Ecology 88:882-890

Pigliucci M (2001) Phenotypic plasticity. Beyond nature and nurture. Johns Hopkins University Press, Baltimore, MD

Pirazzoli PA (2005) Recent changes in air pressure and wind activity on the Atlantic coasts of France and Ireland. J Coast Res 42(Spec Issue):236-252

Pirazzoli PA, Tomasin A (2003) Recent near-surface wind changes in the central Mediterranean and Adriatic areas. Int J Climatol 23:963-973

Postma E, Charmantier A (2007) What 'animal models' can and cannot tell ornithologists about the genetics of wild populations. J Ornithol 148(Suppl 2):633-642

Potti J (1998) Arrival time from spring migration in male pied flycatchers: individual consistency and familial resemblance. Condor 100:702-708

Price TD, Langen T (1992) Evolution of correlated characters. Trends Ecol Evol 7:307-310

Price TD, Qvarnström A, Irwin DE (2003) The role of phenotypic plasticity in driving genetic evolution. Proc R Soc Lond B Biol Sci 270:1433-1440

Prop J, Black JM, Shimmings P (2003) Travel schedules to the high Arctic: Barncale geese trade-off the timing of migration with the accumulation of fat deposits. Oikos 103: 403-414

Pryor SC, Barthelmie RJ (2003) Long-term trends in nearsurface flow over the Baltic. Int J Climatol 23:271-289

Pryor SC, Schoof JT, Barthelmie RJ (2006) Winds of change? Projections of near-surface winds under climate change scenarios. Geophys Res Lett 33:L11702

Pulido F (2000) Evolutionary quantitative genetics of migratory restlessness in the blackcap (Sylvia atricapilla). Edition Wissenschaft, Reihe Biologie, Band 224, Tectum Verlag, Marburg

Pulido F (2006) Adaptation and adaptability of migratory behavior. Acta Zool Sin 52(Suppl):350-353

Pulido F (2007) The genetics and evolution of avian migration. Bioscience 57:165-174

Pulido F, Berthold P (1998) The microevolution of migratory behavior in the blackcap: effects of genetic covariances on evolutionary trajectories. Biol Conserv Fauna 102:206-211

Pulido F, Berthold P (2003) Quantitative genetic analysis of migratory behavior. In: Berthold P, Gwinner E, Sonnenschein E (eds) Avian migration. Springer, Heidelberg, p 53-77

Pulido F, Berthold P (2004) Microevolutionary response to climate change. Adv Ecol Res 35:151-183

Pulido F, Coppack T (2004) Correlation between timing of juvenile molt and onset of migration in the blackcap (Sylvia atricapilla). Anim Behav 68:167-173

Pulido F, Widmer M (2005) Are long-distance migrants constrained in their evolutionary response to environmental change? Causes of variation in the timing of autumn migration in a blackcap (Sylvia atricapilla) and two garden warbler (Sylvia borin) populations. Ann N Y Acad Sci 1046:228-241

Pulido F, Berthold P, van Noordwijk AJ (1996) Frequency of migrants and migratory activity are genetically correlated in a bird population: evolutionary implications. Proc Natl Acad Sci USA 93:14642-14647

Pulido F, Berthold P, Mohr G, Querner U (2001a) Heritability of the timing of autumn migration in a natural bird population. Proc R Soc Lond B Biol Sci 268:953-959

Pulido F, Coppack T, Berthold P (2001b) Genetic variation and phenotypic plasticity may explain adaptive changes in the timing of autumn migration. Ring 23:149-158
Rainio K, Laaksonen T, Ahola M, Vähätalo AV, Lehikoinen E (2006) Climatic responses in spring migration of boreal and arctic birds in relation to wintering area and taxonomy. J Avian Biol 37:507-515

Rainio K, Tøttrup AP, Lehikoinen E, Coppack T (2007) Effects of climate change on the degree of protandry in migratory songbirds. Clim Res 35:107-114

Reed TE, Wanless S, Harris MP, Frederiksen M, Kruuk LEB, Cunningham EJA (2006) Responding to environmental change: plastic responses vary little in a synchronous breeder. Proc R Soc Lond B Biol Sci 273:2713-2719

Rees EC (1989) Consistency in the timing of migration for individual Bewick's swans. Anim Behav 38:384-393

Reznick D, Travis J (1996) The empirical study of adaptation in natural populations. In: Rose ML, Lauder GV (eds) Adaptation. Academic Press, San Diego, CA, p 243-289

Richardson WJ (1978) Timing and amount of bird migration in relation to weather: a review. Oikos 30:224-272

Richardson WJ (1990) Timing of bird migration in relation to weather: updated review. In: Gwinner E (ed) Bird migration. Springer, Heidelberg, p 78-101

Rubolini D, Møller AP, Rainio K, Lehikoinen E (2007) Intraspecific consistency and geographic variability in temporal trends of spring migration phenology among European bird species. Clim Res 35:135-146

Saino N, Szép T, Romano M, Rubolini D, Spina F, Møller AP (2004a) Ecological conditions during winter predict arrival date at the breeding quarters in a trans-Saharan migratory bird. Ecol Lett 7:21-25

Saino N, Szép T, Ambrosini R, Romano M, Møller AP (2004b) Ecological conditions during winter affect sexual selection and breeding in a migratory bird. Proc R Soc Lond B Biol Sci 271:681-686

Saino N, Rubolini D, Jonzén N, Ergon T, Montemaggiori A, Stenseth NC, Spina F (2007) Temperature and rainfall anomalies in Africa predict timing of spring migration in trans-Saharan migratory birds. Clim Res 35:123-134

Sanderson FJ, Donald PF, Pain DJ, Burfield IJ, van Bommel FPJ (2006) Long-term population declines in Afro-Palearctic migrant birds. Biol Conserv 131:93-105

Sanz JJ, Potti J, Moreno J, Merino S, Frías O (2003) Climate change and fitness components of a migratory bird breeding in the Mediterranean region. Glob Change Biol 9: $461-472$

Schaub M, Jenni L (2001) Variation of fuelling rates among sites, days and individuals in migrating passerine birds. Funct Ecol 15:584-594

Schwartz MD, Ahas R, Aasa A (2006) Onset of spring starting earlier across the Northern Hemisphere. Glob Change Biol 12:343-351

Sheldon BC, Kruuk LEB, Merilä J (2003) Natural selection and inheritance of breeding time and clutch size in the collared flycatcher. Evolution 57:406-420

Sinelschikova A, Kosarev V, Panov I, Baushev AN (2007) The influence of wind conditions in Europe on the advance of the spring migration of the song thrush (Turdus philomelos) in the south-east Baltic region. Int J Biometeorol 51:431-440

Smith RJ, Moore FR (2005) Arrival timing and seasonal reproductive performance in a long-distance migratory landbird. Behav Ecol Sociobiol 57:231-239

Sokolov LV, Kosarev VV (2003) Relationship between timing of arrival of passerines to the Courish Spit and North Atlantic Oscillation index (NAOI) and precipitation in Africa. Proc Zool Inst Russ Acad Sci 299:141-154

Sokolov LV, Markovets MY, Shapoval AP, Morozov YG (1998) Long-term trends in the timing of spring migration of 
passerines on the Courish Spit of the Baltic Sea. Avian Ecol Behav 1:1-21

Solomon S, Qin D, Manning M, Chen Z and others (eds) (2007). Climate Change 2007: the physical science basis. Contribution of Working Group I to the Fourth Assessment Report of the Intergovernmental Panel on Climate. Cambridge University Press, Cambridge

Sparks T, Tryjanowski P (2007) Patterns of spring arrival dates differ in two hirundines. Clim Res 35:159-164

Sparks TH, Bairlein F, Bojarinova JG, Hüppop O and others (2005) Examining the total arrival distribution of migratory birds. Glob Change Biol 11:22-30

Sternberg H, Grinkov VG (2006) The effect of hatching date on arrival time in spring, and the timing of breeding in male pied flycatchers. J Ornithol 147(Suppl):108

Stervander M, Lindström Á, Jonzén N, Andersson A (2005) Timing of spring migration in birds: long-term trends, North Atlantic Oscillation and the significance of different migration routes. J Avian Biol 36:210-221

Stewart RLM, Francis CM, Massey C (2002) Age-related differential timing of spring migration within sexes in passerines. Wilson Bull 114:264-271

Strode PK (2003) Implications of climate change for North American wood warblers (Parulidae). Glob Change Biol 9:1137-1144

Studds CE, Marra PP (2005) Nonbreeding habitat occupancy and population processes: an upgrade experiment with a migratory bird. Ecology 86:2380-2385

Studds CE, Marra PP (2007) Linking fluctuations in rainfall to nonbreeding season performance in a long-distance migratory bird, Setophaga ruticilla. Clim Res 35:115-122

Sutherland W (1998) Evidence for flexibility and constraint in migration systems. J Avian Biol 29:441-446

Terrill SB, Berthold P (1990) Ecophysiological aspects of rapid population growth in a novel migratory blackcap population (Sylvia atricapilla): an experimental approach. Oecologia 85:266-270

Thompson JD (1991) Phenotypic plasticity as a component of evolutionary change. Trends Ecol Evol 6:246-249

Tøttrup AP, Thorup K, Rahbeck C (2006) Patterns of change in timing of spring migration in North European songbird populations. J Avian Biol 37:84-92

Tryjanowski P, Sparks TH, Ptaszyk J, Kosicki J (2004) Do white storks Ciconia ciconia always profit from an early return to their breeding grounds? Bird Study 51:222-227

Vähätalo AV, Rainio K, Lehikoinen A, Lehikoinen E (2004) Spring arrival of birds depends on the North Atlantic Oscillation. J Avian Biol 35:210-216

Valiela I, Bowen JL (2003) Recent shifts in winter distribution in birds: effects of global warming and local habitat change. Ambio 32:476-480

Submitted: August 13, 2007; Accepted: October 30, 2007 van Asch M, Visser ME (2007) Phenology of forest caterpillars and their host trees: the importance of synchrony. Annu Rev Entomol 52:37-55

van Noordwijk AJ, Pulido F, Helm B, Coppack T and others (2006) A framework for the study of genetic variation in migratory behaviour. J Ornithol 147:221-233

Visser ME, Both C (2005) Shifts in phenology due to global climate change: the need for a yardstick. Proc R Soc Lond B Biol Sci 272:2561-2569

Visser ME, Both C, Lambrechts MM (2004) Global climate change leads to mistimed avian reproduction. Adv Ecol Res 35:89-110

Walther GR, Post E, Convey P, Menzel A and others (2002) Ecological responses to recent climate change. Nature 416:389-395

Weidinger K, Král M (2007) Climatic effects on arrival and laying dates in a long-distance migrant, the collared flycatcher Ficedula albicollis. Ibis 149:836-847

Wernham C, Toms M, Marchant J, Clark J, Siriwardena G, Baillie S (2002) The migration atlas. Movements of birds of Britain and Ireland. Poyser, London

Widmer M (1999) Altitudinal variation of migratory traits in the garden warbler Sylvia borin. PhD thesis, University of Zurich

Widmer M, Biebach H (2001) Changes in body condition from spring migration to reproduction in the garden warbler Sylvia borin: a comparison of a lowland and a mountain population. Ardea 89:57-68

Wikelski M, Kays RW, Kasdin NJ, Thorup K, Smith JA, Swenson GW (2007) Going wild: what a global small-animal tracking system could do for experimental biologists. J Exp Biol 210:181-186

Wingfield JC, Hahn TP, Levin R, Honey P (1992) Environmental predictability and control of gonadal cycles in birds. J Exp Zool 261:214-231

Wingfield JC, Hahn TP, Wada M, Astheimer LB, Schoech S (1996) Interrelationship of day length and temperature on the control of gonadal development, body mass, and fat scores in white-crowned sparrows, Zonotrichia leucophrys gambelii. Gen Comp Endocrinol 101:242-255

Wingfield JC, Hahn TP, Maney DL, Schoech SJ, Wada M, Morton ML (2003) Effects of day length and temperature on photoperiodically induced reproductive development, circulating plasma luteinizing hormone and thyroid hormones, body mass, fat deposition and molt in mountain white-crowned sparrows, Zonotrichia leucophrys oriantha. Gen Comp Endocrinol 131:143-158

Zalakevicius M, Bartkeviciene G, Raudonikis L, Janulaitis J (2006) Spring arrival response to climate change in birds: a case study from eastern Europe. J Ornithol 147: $326-343$

Proofs received from author(s): December 24, 2007 